\title{
Combinatorial optimization and Green Logistics
}

\author{
Abdelkader Sbihi • Richard W. Eglese
}

Received: 23 February 2007 / Revised: 20 April 2007 / Published online: 1 June 2007

(C) Springer-Verlag 2007

\begin{abstract}
The purpose of this paper is to introduce the area of Green Logistics and to describe some of the problems that arise in this subject which can be formulated as combinatorial optimization problems. The paper particularly considers the topics of reverse logistics, waste management and vehicle routing and scheduling.
\end{abstract}

Keywords Green Logistics · Reverse Logistics - Combinatorial optimization • Waste management · Hazardous materials

MSC classification (2000) $90 \mathrm{C} 10 \cdot 90 \mathrm{C} 35 \cdot 90 \mathrm{C} 59 \cdot 90 \mathrm{C} 90$

\section{Introduction}

Green Logistics is concerned with producing and distributing goods in a sustainable way, taking account of environmental and social factors. Thus the objectives are not only concerned with the economic impact of logistics policies on the organization carrying them out, but also with the wider effects on society, such as the effects of pollution on the environment. Green Logistics activities include measuring the environmental impact of different distribution strategies, reducing the energy usage in logistics activities, reducing waste and managing its treatment. In recent years there has been increasing concern about the environmental effects on the planet of human activity and current logistic practices may not be sustainable in the long term.

\footnotetext{
A. Sbihi · R. W. Eglese $(\varangle)$

Department of Management Science, Lancaster University Management School,

Lancaster, LA1 4YX, UK

e-mail: a.sbihi@lancaster.ac.uk

R. W. Eglese

e-mail: r.eglese@lancaster.ac.uk
} 
Many organizations and businesses are starting to measure their carbon footprints so that the environmental impact of their activities can be monitored. Governments are considering targets for reduced emissions and other environmental measures. There is therefore increasing interest in Green Logistics from companies and governments.

Traditional logistics models for production and distribution have concentrated on minimizing costs subject to operational constraints. But consideration of the wider objectives and issues connected with Green Logistics leads to new methods of working and new models, some of which pose interesting new applications for operational research models of various types. A survey of all operational research models in this area would require a very long article and so the focus of this paper is to concentrate on some of the new or revised combinatorial optimization models that arise in Green Logistics applications. For those working in combinatorial optimization it is hoped that these new models will pose interesting new challenges that may have significant effects on the environment when the results are applied.

This paper discusses different areas that relate to the Green Logistics agenda. Section 2 concerns Reverse Logistics models that take account of the full life-cycle of a product and the possibilities of various forms of recycling. Section 3 covers waste management that includes models for the transportation of hazardous waste, roll-on roll-off containers and the collection of household waste. Section 4 deals with vehicle routing models and issues relating to Green Logistics objectives. Section 5 contains the final conclusions.

\section{Reverse Logistics}

There are various definitions of Reverse Logistics to be found in the literature. For example, Fleischmann et al. (1997) say that reverse logistics is "a process which encompasses the logistics activities all the way from used products no longer required by the user to products again usable in a market". Dowlatshahi (2000) explains Reverse Logistics as "a process in which a manufacturer systematically accepts previously shipped products or parts from the point for consumption for possible recycling, remanufacturing or disposal'. Later, the European Working Group on Reverse Logistics, REVLOG, Dekker et al. (2004), give this definition: "The process of planning, implementing and controlling backward flows of raw materials, in process inventory, packaging and finished goods, from a manufacturing, distribution or use point, to a point of recovery or point of proper disposal".

In their book, Rogers and Tibben-Lembke (1999) briefly consider the differences between Reverse Logistics and Green Logistics. In Reverse Logistics there should be some flow of products or goods back from the consumer to an earlier stage of the supply chain. The reduction of waste that this implies certainly means that Reverse Logistics should be included within Green Logistics. For example, De Brito and Van Der Laan (2003) examine inventory management issues when product returns must be estimated. However there will be other models of logistics activities involving only forward flows of goods that could not be described as reverse logistics, but if they include environmental considerations, will also be included within Green Logistics. For example, Mondschein and Schilkrut (1997) describe a mixed integer linear pro- 
gramming model to determine the optimal investment policies for the copper industry in Chile. A key part of the model was to control air pollution through emissions in the production process.

Legislation within the European Community gives high importance to recycled products and, in some cases, it has established the responsibility for the end of life products to the manufacturers. For example, the Waste Electronic and Electrical Equipment (WEEE) Directive $(2002 / 96 / E C)^{1}$ deals with this. Such legislation is one of the drivers in establishing the importance of reverse logistics operations. Most European companies will increasingly have to think about incorporating Reverse Logistics activities in their business operations.

\subsection{Location models used in Reverse Logistics}

There is a huge amount of research in facility location theory in general. However, in the literature we found relatively few papers on this topic applicable to Reverse Logistics (RL). Krikke (1998) proposes some models for RL network design. He designs a model for a multi-product and multi-echelon situation. The model allows new facilities to be added with the corresponding cost functions when necessary. He proposes the design of a network graph and a transportation graph as basic inputs for his model. Barros et al. (1998) consider the problem of the recycling of sand (a subproduct of recycling construction waste) in the Netherlands. They propose a two-level location model for the sand problem and consider its optimization using heuristic procedures. Fleischmann et al. (2000) reviewed nine published case studies on logistics network design for product recovery in different industries, and identified some general characteristics of product recovery networks, comparing them with traditional logistics structures. They classified the product recovery networks in three sub-areas: re-usable item networks, remanufacturing networks, and recycling networks.

Other references deal with this topic (e.g., Krikke 1998; Sarkis 2001; Fleischmann 2001). Most of the models developed in this field are similar to the traditional location problems, in particular location-allocation models (see Kroon and Vrijens 1995; Ammons et al. 1999; Spengler et al. 1997; Marìn and Pelegrìn 1998; Jayaraman et al. 1999; Krikke et al. 1999, 2001; ?). In most of the models, transportation and processing costs were minimized while the environmental costs associated with the designed network were often neglected.

\subsection{Dynamic lot sizing problem}

The dynamic lot sizing problem in its simplest form considers a facility, possibly a warehouse or a retailer, which faces dynamic demand for a single item over a finite horizon (see Wagner and Whitin 1958). The facility places orders for the item from a supply agency, e.g., a manufacturer or a supplier, which is assumed to have an unlimited quantity of the product. The model assumes a fixed ordering (setup) cost, a linear

1 http://eur-lex.europa.eu/LexUriServ/LexUriServ.do?uri=CELEX: 32002L0096:EN:HTML (accessed 20/02/2007) 
procurement cost for each unit purchased, and a linear holding cost for each unit held in inventory per unit time. Given the time varying demand and cost parameters, the problem is to decide when and how much to order at the facility in each period so that all demand is satisfied at minimum cost. We can mathematically formulate this problem as follows:

$$
\left\{\begin{array}{lll}
\text { Minimize } & \sum_{t=1}^{T}\left\{K \delta_{t}+h^{s} I_{t}^{s}\right\} & \\
\text { s.t. } & I_{t-1}^{s}+x_{t}^{m}-D_{t}=I_{t}^{s} & \forall t \in\{1, \ldots, T\} \\
& x_{t}^{m} \leq M_{t} \delta_{t} & \forall t \in\{1, \ldots, T\} \\
& M_{t}=\sum_{i=t}^{T} D_{i} & \forall t \in\{1, \ldots, T\} \\
& x_{t}^{m}, I_{t}^{s} \geq 0, \quad \delta_{t} \in\{0,1\} & \forall t \in\{1, \ldots, T\} .
\end{array}\right.
$$

In this formulation, $K$ represents the cost of a set-up and $h^{s}$ is the cost of holding a unit of stock per unit time. $I_{t}^{S}$ is the serviceable stock held at time $t$ and $D_{t}$ is the demand in time $t$. It is assumed that $D_{t}$ is known or can be predicted accurately. $T$ represents the time horizon over which the lot sizing decisions are to be taken and $x_{t}^{m}$ is the amount to be manufactured in time $t$. The objective function minimizes the total cost of production, set up and inventory. Constraint (1) is the demand balance equation: the inventory from the previous period and the production from the current period can be used to meet demand in this period or to build up inventory to satisfy later demand. In each period with non-zero production a set up is incurred. This is modeled in the fixed charge constraint (2). Constraint (3) ensures that $M_{t}$ is sufficiently large for use in constraint (2).

The dynamic lot-sizing problem has been well studied in the past since it was first introduced more than four decades ago. The exact solution technique, known as the Wagner-Whitin algorithm, based on Dynamic Programming is well known in production planning and inventory control. For more information about this model, see the books by Bramel and Simchi-Levi (1997), Johnson and Montgomery (1974), and Silver et al. (1996). A variety of heuristic methods have also been proposed, for example the Silver-Meal heuristic described in Silver and Meal (1973).

In Teunter et al. (2006) a variant of the basic lot sizing model is considered where the serviceable stock may also be made using a remanufacturing operation that utilizes returns and produces serviceable stock that is indistinguishable from the newly manufactured stock. Examples of remanufacturing include single-use cameras and copiers. An inventory system with remanufacturing can be described in Fig. 1.

The model studied makes the following assumptions:

- no disposal option for returns;

- holding cost for serviceables is greater than holding cost for returns;

- variable manufacturing and remanufacturing costs are not included.

The objective is again to minimize the sum of the set-up costs and holding costs. Two variants are considered. In the first it is assumed that there is a joint set-up cost for manufacturing and remanufacturing which is appropriate when the same production 


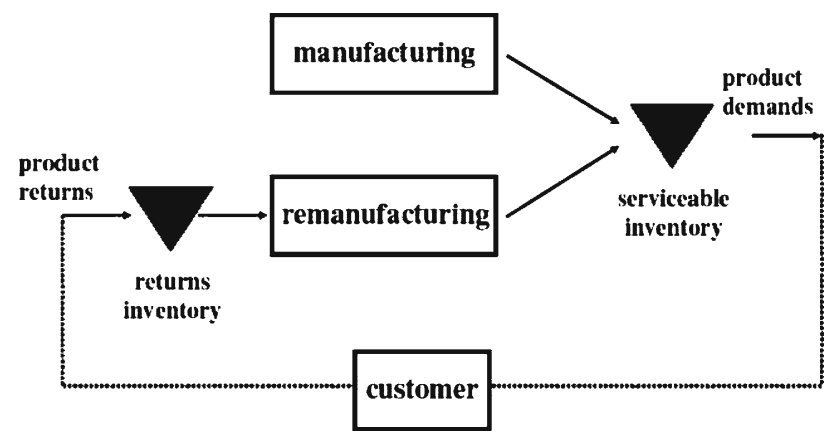

Fig. 1 An inventory system with remanufacturing

line is used for both processes. The second variant assumes separate set-up costs for manufacturing and remanufacturing. We review these models in the next two sections.

\subsection{Joint set-up cost model}

The model with a joint set-up cost for manufacturing and remanufacturing is suitable if manufacturing and remanufacturing operations are performed on the same production line using the same production resources. The mathematical formulation of the joint set-up cost model is as follows:

$$
\left\{\begin{array}{lll}
\text { Minimize } & \sum_{t=1}^{T}\left\{K \delta_{t}+h^{r} I_{t}^{r}+h^{s} I_{t}^{s}\right\} & \\
\text { s.t. } & I_{t-1}^{r}+R_{t}-x_{t}^{r}=I_{t}^{r} & \\
& I_{t-1}^{s}+x_{t}^{r}+x_{t}^{m}-D_{t}=I_{t}^{s} & \forall t \in\{1, \ldots, T\} \\
& x_{t}^{r}+x_{t}^{m} \leq M_{t} \delta_{t} & \forall t \in\{1, \ldots, T\} \\
& M_{t}=\sum_{i=t}^{T} D_{i} & \forall t \in\{1, \ldots, T\} \\
& x_{t}^{r}, x_{t}^{m}, I_{t}^{r}, I_{t}^{s} \geq 0, \quad \delta_{t} \in\{0,1\} & \forall t \in\{1, \ldots, T\} .
\end{array}\right.
$$

$I_{t}^{r}$ represents the stock of returned items and $h^{r}$ is the cost of holding a returned item per unit time. $R_{t}$ represents the number of returned items in period $t$ and $x_{t}^{r}$ is the amount remanufactured in time $t$. Constraints (5) and (6) assure the inventory balance in return and serviceable stocks, respectively. Constraint (7) keeps track of the set-ups; whenever a manufacturing and/or a remanufacturing lot is produced, a set-up is made and the production (the sum of the amount manufactured and remanufactured) in period $t$ will never exceed the total demand in periods $t, \ldots, T$.

Teunter et al. (2006) prove two lemmas for this model, which provide the basis for an exact dynamic programming algorithm and some heuristics. The first lemma states that for any optimal solution, the stock of serviceable items at the beginning of any period with a set-up is zero. This lemma is a generalization of the well-known zero-inventory property for the original lot sizing problem without returns. The second 
lemma shows that priority is given to the remanufacturing option, i.e., that any optimal solution only manufactures in a certain period if the initial stock of returns at the beginning of that period is insufficient for remanufacturing the entire lot.

Teunter et al. (2006) propose two types of solution method for the joint set-up model. The first is a dynamic programming algorithm that is a generalized version of the Wagner and Whitin algorithm for solving the dynamic lot sizing problem without returns. This algorithm is of $O\left(T^{4}\right)$ and takes a fraction of a second for a number of periods of $T=12$. The second approach modifies heuristics that have been proposed for the original lot sizing problems.

\subsection{Separate set-up cost model}

The lot sizing problem under separate manufacturing and remanufacturing set-up costs is suitable for situations where there are separate production lines, one for manufacturing and one for remanufacturing. This model can be formulated as follows:

$$
\left\{\begin{array}{lll}
\text { Minimize } & \sum_{t=1}^{T}\left\{K^{r} \delta_{t}^{r}+K^{m} \delta_{t}^{m}+h^{r} I_{t}^{r}+h^{s} I_{t}^{s}\right\} & \\
\text { s.t. } & I_{t-1}^{r}+R_{t}-x_{t}^{r}=I_{t}^{r} & \forall t \in\{1, \ldots, T\} \\
& I_{t-1}^{r}+x_{t}^{r}+x_{t}^{m}-D_{t}=I_{t}^{s} & \forall t \in\{1, \ldots, T\} \\
& x_{t}^{r} \leq M_{t} \delta_{t}^{r} & \forall t \in\{1, \ldots, T\} \\
x_{t}^{m} \leq M_{t} \delta_{t}^{m} & \forall t \in\{1, \ldots, T\} \\
& M_{t}=\sum_{i=t}^{T} D_{i} & \forall t \in\{1, \ldots, T\} \\
& x_{t}^{r}, x_{t}^{m}, I_{t}^{r}, I_{t}^{s} \geq 0, \quad \delta_{t}^{r}, \delta_{t}^{m} \in\{0,1\} & \forall t \in\{1, \ldots, T\} .
\end{array}\right.
$$

$K^{r}$ and $K^{m}$ refer to the set-up costs for remanufacturing and manufacturing, respectively.

Although, this appears to be only a small change to the structure of the model, Teunter et al. (2006) provide examples to show that the lemmas proved for the joint set-up model do not hold for the separate set-up cost model. They conjecture that the problem with separate set-up costs is NP-hard, but this has not yet been proved, though Van Den Heuvel (2004) has shown that the problem is NP-hard when (re)manufacturing costs are included. Teunter et al. (2006) propose and test some heuristics for this model.

This example illustrates how new models required for reverse logistics may lead to challenging new combinatorial optimization problems of a theoretical and practical nature.

\section{Waste management}

The widely acknowledged increase in solid waste production, together with the increased concern about environmental issues, have led local governments and agencies to devote resources to solid waste collection policy planning. Waste management 
is a key process to protect the environment and conserve resources. In recent years, policies of governments towards waste management have focused on waste avoidance, reuse and recycling. As a result there has been significant progress in these management areas, particularly for the more developed nations. The environmental aspects of waste management means that activities concerning the transport of waste materials are clearly part of the Green Logistics agenda.

\subsection{Hazardous waste}

Many households and businesses use hazardous materials in their day to day activities. Many of these activities produce waste that can injure or even threaten living things. This type of waste is known as hazardous waste. Hazardous waste must be handled in special ways to prevent threats to human health and the environment. Paint products, solvents, some batteries, household cleaners and pesticides are typical examples. If they were sent to a landfill site or otherwise improperly managed, these materials might contaminate the ground water from which drinking supplies are taken, so special regulations cover their disposal. When transported, the risks of hazardous waste may need to be considered as well as economic considerations.

In the past, many researchers and environmental engineers have attempted to address the problem of hazardous waste management with the aid of various mathematical models. Peirce and Davidson (1982) applied a linear programming technique to identify a cost-effective configuration of transportation routes, transfer stations, processing facilities and secure long-term storage impoundments. Fleischmann et al. (1997) did a systematic overview of the issues arising in the context of reverse logistics. They discussed the implications of the emerging reuse efforts and reviewed the mathematical models proposed in the literature. Giannikos (1998) presented a multiobjective model for locating disposal or treatment facilities and transporting hazardous waste along the links of a transportation network. Four objectives were considered: (1) minimization of total operating cost; (2) minimization of total perceived risk; (3) equitable distribution of risk among population centres; and (4) equitable distribution of the disutility caused by the operation of the treatment facilities. A goal programming model was proposed to solve the problem.

Nema and Gupta (1999) proposed a model based on a multiobjective integer programming approach to suggest the optimal configuration of facilities for transportation, treatment and disposal with minimum cost and minimum risk to the environment. Nema and Gupta (2003) later improved upon their suggested model based on a utility function approach by basing the model on integer goal programming. The model was able to address practical issues such as multiple objectives, compatibility between waste types, compatibility between waste and waste technologies and the waste residue generation associated with treatment technologies. Hu et al. (2002) presented a cost-minimization model for a multi-time-step, multiple-type hazardous waste reverse logistics system. The model addressed the classical hazardous waste treatment problem with a systematic management strategy rather than with waste treatment technologies as conventionally employed. Shih and Lin (2003) presented a multiple criteria optimization approach that considered minimization of the cost, risk and workload for 
collection system planning for infectious medical waste. A compromise programming method was used to integrate the three objectives, and an example of a collection of infectious waste in Taiwan City was presented. White et al. (2003), with the help of a case study, described the recovery of computers as a step-by-step process and also framed an environmental research agenda for recovery management.

None of the above mathematical formulations address all components of a complete solid waste management system, and most of them do not address the reverse flow of waste, which is necessary for addressing special waste streams such as computer waste. In addition, the generation of waste at any source node varies with time and so it is advisable to have a multi-time step model that takes into account such variations. Moreover, the above models do not also take into account the uncertainty associated with the data related to waste generation. Furthermore, risk, as addressed in most of the models, is usually only considered for the transportation of hazardous waste. There is a need for it to be accounted for at every stage, including storage, segregation, treatment and disposal facilities.

\subsection{Logistics of skips or roll-on roll-off containers}

Skips or roll-on roll-off containers are used to carry waste in a wide variety of situations. They may be hired by companies or members of the public who want to dispose of large amounts of building or garden waste. A typical operation is described in De Meulemeester et al. (1997). Vehicles start at a depot and have to deliver empty skips to customers, collect full skips from customers and deliver the full skips to either the depot or one of the disposal facilities. A vehicle has the capacity to carry one skip at a time. Skips can be of multiple types and this is a restriction in exchanging full for empty. De Meulemeester et al. (1997) develop two heuristics and an exact procedure for solving this problem. The exact procedure is based on enumeration. The first heuristic is based on the classical Clarke and Wright (1964) savings heuristic. The second heuristic calculates a solution to a formulated transportation problem, providing a lower bound to the optimal solution. The solution to the transportation problem is made feasible in a number of heuristic steps. On average, the variant of the Clarke and Wright savings algorithm performed best.

Bodin et al. (2000) describe a variant of this problem called the roll-on-roll-off vehicle routing problem (RRVRP). In a RRVRP trip, a truck with a capacity for one container departs from a depot to serve customers who need a container placed, collected or exchanged (full for empty). The network consists of only one depot and one disposal facility and all containers are of the same type. In that sense the model of Bodin et al. (2000) is a simplification of the real-life case of De Meulemeester et al. (1997). Bodin et al. (2000) develop four types of algorithms. The first algorithm is again an adaptation of the Clarke and Wright heuristic. The second algorithm is a trip insertion and trip improvement heuristic. The third algorithm is a so-called decomposition algorithm, which starts by enumerating routes, followed by solving a set covering problem. The resulting solution is improved with some swaps. The last and most advanced algorithm is a truncated dynamic programming heuristic, generating partial solutions that are completed by adding the orders not covered by solving a 
bin-packing model. The dynamic programming algorithm performs the best, although calculation times are long. The other algorithms are faster, but the trip insertion and trip improvement heuristics in particular are not competitive in terms of solution quality.

Archetti and Speranza (2004) describe another variant of the problem, the so called 1-skip collection problem (1-SCP). As the name indicates, vehicle capacity is limited to one skip or container. Since Archetti and Speranza deal with a real-life problem, they consider several practical restrictions such as multiple container types, time windows, different priorities for different customers and a limited fleet size. Archetti and Speranza develop a three-phase algorithm. In phase 1, the set of skips that needs to be collected that day is determined and ranked in priority. In phase 2 , a solution for the subset of skips is constructed. In phase 3, the solution is further improved by using local search procedures.

\subsection{Household Waste Collection}

The waste collection "problem" is naturally complex, as there is a large number of factors and associated constraints to consider. For accurate modelling, information is needed about:

- expected volumes and/or weights of the different waste types to be collected and the seasonal variability;

- current waste collection system (weekly, alternate weekly, ...) and potential future options;

- collection frequencies;

- locations of the collection points and access restrictions;

- locations of the available disposal and treatment sites and their opening hours;

- locations of the available vehicle depots and their opening hours;

- numbers and capacities of available vehicles;

- crew requirements and shift operating structures;

- road network restrictions, such as avoiding busy streets during peak hours and narrow streets;

- costs associated with waste collection and disposal.

Solid waste collection in urban areas is a key topic for local environmental agencies. The operational problem, the definition of collection routes given the vehicle fleet, is an important combinatorial optimization problem and software is available to help manage this issue (see e.g., Sahoo et al. 2005).

Routing problems are typically treated as being either an arc routing problem, where all of the arcs (lines or roads) of the network must be traversed, or a node routing problem, where all of the nodes (points or places) on the network must be visited. Household waste collection is naturally described as an arc routing problem (ARP), as collections normally have to be made from all the houses on a street (arc). The ARP is a natural way to model waste collection problems in cases where most or all bins along a given street segment must be collected at the same time, and most of the street segments must be traversed by the collection vehicle as is the case in densely populated city areas. A comprehensive survey of Arc Routing Problems is provided in the book edited by Dror (2000). 
In situations where household waste is brought together at a number of designated collection points, the operation can be modelled as a node routing problem, which will be similar to many other conventional vehicle routing problems.

In practical applications there will be many constraints that need to be taken into account such as the capacity of the collection vehicles, time windows for collection and the locations of landfills or other facilities where the waste collected can be disposed. In addition, there will need to be information about the underlying road network and whether it needs to be modelled as an undirected, directed or mixed graph.

Issues for a typical waste management operation are covered in Sahoo et al. (2005). In particular the paper discusses the districting problem: how to divide the area from which waste is to be collected into districts in order to subdivide the problem and make it more manageable.

The issue of recycling different categories of household waste is leading to new vehicle routing problems for household waste collection. For example, Mansini and Speranza (1998) describe a case study concerning the collection of waste and recyclables in Brescia. Beullens et al. (2003) consider the issue of what savings are possible by co-collection, i.e., collecting recyclable items and waste for disposal at the same time using vehicles with appropriate separate compartments. They show that co-collection can result in a significant reduction in routing costs. However there may be more practical constraints to consider in terms of the availability and suitability of multi-compartment vehicles.

\subsection{Arc routing problems}

As has been explained in the previous section, many waste collection models are based on arc routing problems. The capacitated arc routing problem (CARP) (see Golden and Wong 1981) in its undirected version is defined as follows. Let $G=(V, E)$ be an undirected graph with a set $V$ of $n$ nodes (vertices) and a set $E$ of $m$ edges. A fleet of identical vehicles of capacity $W$ is based at a depot node $s$. The number of vehicles is either fixed or left as a decision variable. A subset of $\tau$ edges, denoted as required edges or tasks, require service by a vehicle. All edges can be traversed any number of times. Each edge $(i, j)$ has a traversal cost $c_{i j}$ and a demand $q_{i j}$. All costs and demands are integers. The goal is to determine a set of vehicle trips (routes) of minimum total cost, such that each trip starts and ends at the depot, each required edge is serviced by one single trip, and the total demand handled by any vehicle does not exceed $W$.

Since the CARP is NP-hard, large-scale instances must be solved in practice with heuristics. Among fast constructive methods, there are for instance Augment-Merge, (Golden and Wong 1981), path-scanning (Golden et al. 1983) and Ulusoy's splitting technique (Ulusoy 1985). Available metaheuristics include tabu search algorithms, (Eglese and Li 1996; Hertz et al. 2000) and a tabu search combined with scatter search components, (Greistorfer 2003), a variable neighborhood search, (Hertz et al. 2001), a guided local search, (Beullens et al. 2003), and hybrid genetic algorithms (Moscato 1999; Dellaert and Jeunet 2000). More recently Lacomme et al. (2004) have produced a memetic algorithm and Brandão and Eglese (2006) have proposed a deterministic tabu 
search algorithm. All these heuristics can be evaluated thanks to tight lower bounds, (Benavent et al. 1992; Mourão and Almeida 2000).

The single objective CARP only deals with minimizing the total cost of the trips. In fact, many waste management companies are also interested in balancing the trips. For instance, in several cities, all trucks leave the depot at 6 a.m. and waste collection must be completed as soon as possible to assign the crews to other tasks, e.g., sorting the waste at a recycling facility. Hence, the company wishes to solve a bi-objective version of the CARP, in which both the total duration of the trips and the duration of the longest trip (corresponding to the makespan in scheduling theory) are to be minimized. This type of ARP is called a bi-objective CARP which has been presented at the EMO conference by Lacomme et al. (2003).

Another variant is the periodic arc routing problem which consists of selecting for each street a number of treatment days equal to its frequency (tactical decisions), and then of computing the trips for the streets assigned to each day (operational decisions). The total cost over the horizon depends on this combination of assignment and routing decisions. Waste collection is just one example. A similar organisation can be found in other applications like winter gritting, sweeping, inspection of power lines, or spraying herbicides on rails or roads to kill weeds. In this context, it is clear that the basic CARP must be considered as a single-period problem that cannot account for this complexity.

To the best of our knowledge, there are only a few published papers that deal with periodic arc routing, (Lacomme et al. 2005; Chu et al. 2005, 2006). A related issue involves setting the collection frequency for different types of waste. This period routing problem is discussed in Teixeira et al. (2004) which refers to an application of collecting recyclables in a district of Portugal.

We present here a basic form of this variant. We consider a network $G=(V, E)$ and a discrete time horizon $H$ of $n p$ periods or "days", in which each task $u$, which involves servicing an edge, has a frequency $f(u)$. This means that the edge corresponding to $u$ must be serviced $f(u)$ times, $1 \leq f(u) \leq n p$, but at most once per day. The total number of services $n s$ to be performed in $H$ is then the sum of all task frequencies. The basic periodic CARP (PCARP) consists of selecting $f(u)$ distinct days for each task $u$ and solving the $n p$ resulting CARPs, to minimize the total cost of the trips over $H$. It is obviously NP-hard, since it includes the single-period CARP as special a case.

In fact, the CARP as defined on an undirected graph is too simplistic to model real street networks encountered for instance in urban refuse collection. The undirected graph can only model two-way streets whose two sides are collected in parallel and in either direction. Even if this practice is common in low-traffic areas, actual networks also include two-way streets with independent collections from each side and one-way streets. Clearly, such extensions can be tackled by extending the CARP with a mixed network, leading to a new problem called Mixed CARP or MCARP (see Belenguera et al. 2006). The MCARP is NP-hard, since it includes NP-hard particular cases: the CARP or UCARP (undirected graph), the Directed CARP or DCARP (directed graph), the mixed rural postman problem or MRPP (if the capacity of the vehicles $Q=\infty$ ) and the mixed Chinese postman problem or MCPP (if $Q=\infty$ and all links are required). 
Different formulations can be used as a basis for solving arc routing problems. The natural formulation is to work with variables representing the arcs (or edges) on the underlying graph and this is likely to be advantageous when the underlying graph is sparse, as is the case with many road networks. However an alternative approach is to transform the arc routing problem to a corresponding node routing problem. Then a node routing algorithm can be used to solve the problem.

Pearn et al. (1987) showed how a CARP with $n$ edges can be converted into a corresponding vehicle routing problem with $(3 n+1)$ nodes. More recently Baldacci and Maniezzo (2006) showed how an equivalent node routing problem could be created by introducing a pair of nodes for each required edge and defining a new graph with distances between the nodes that have the required properties so that the solution of the node routing problem on the new graph will be equivalent to solving the CARP on the original graph. Longo et al. (2006) use a similar transformation of the graph but introduce additional constraints instead of changing the distances to produce an equivalent node routing problem. Both of the last two approaches have allowed improved lower bounds to be found for standard CARP instances. Aminu and Eglese (2006) have considered arc routing problems with time windows. Their solution approach involves transforming the problem to an equivalent node routing problem but with additional constraints. A constraint programming approach is used to solve the resulting model.

\section{Vehicle routing and scheduling}

The vehicle routing and scheduling problem (VRSP) concerns the determination of routes and schedules for a fleet of vehicles to satisfy the demands of a set of customers. The basic capacitated vehicle routing problem (CVRP) can be described in the following way. We are given a set of homogeneous vehicles each of capacity $Q$, located at a central depot and a set of customers with known locations and demands to be satisfied by deliveries from the central depot. Each vehicle route must start and end at the central depot and the total customer demand satisfied by deliveries on each route must not exceed the vehicle capacity, $Q$. The objective is to determine a set of routes for the vehicles that will minimize the total cost. The total cost is usually proportional to the total distance traveled if the number of vehicles is fixed and may also include an additional term proportional to the number of vehicles used if the number of routes may vary.

The CVRP and many of its variants have been well studied in the literature since its introduction by Dantzig and Ramser (1959). Its exact solution is difficult to determine for large-scale problems as it is a member of the class of NP-hard problems. Specialised algorithms are able to consistently find optimal solutions for cases with up to about 50 customers; larger problems have been solved to optimality in some cases, but often at the expense of considerable computing time.

In practice, other variations and additional constraints that must be taken into consideration usually make the vehicle routing problem even more difficult to solve to optimality. So many solution procedures are based on heuristic algorithms that are designed to provide good feasible solutions within an acceptable computing time, but without a guarantee of optimality. 
There are several books and survey articles that summarize different approaches and provide references to the large number of journal articles that have been written on this topic (e.g., Golden and Assad 1988; Toth and Vigo 2001). There are many other research works about the classical CVRP. Some exact methods have been tailored for this problem (e.g., Laporte and Nobert 1987; Agarwal et al. 1989; Lysgaard et al. 2004; Fukasawa et al. 2006). Others have proposed approximate methods and heuristics due to the complexity of the problem and the need to solve it in a reasonable computing time (see Laporte and Semet 2002; Cordeau and Laporte 2004; Cordeau et al. 2005; Gendreau et al. 2002). Most of these approaches are based on local search techniques.

Most papers assume that the costs and times of traveling between the depot and the customers and between customers are known and fixed. They are either given or calculated using a shortest path algorithm on the graph or network representing the locations. In practice, the times and shortest paths may vary, particularly by time of day.

\subsection{Vehicle routing and emissions}

The vehicle routing and scheduling problem (VRSP) concerns the determination of routes and schedules for a fleet of vehicles to satisfy the demands of a set of customers. The VRSP includes the CVRP as the simplest case. There is not much literature that links VRSP models with the Green Logistics issues that have been discussed in the previous section. Most articles are concerned with objectives of minimizing economic costs. Commercial software is also designed to provide feasible solutions that will minimize economic costs. Many software vendors claim that the use of their VRSP package will result in economic benefits for their customers from reductions in the number of vehicles required and distance traveled compared with traditional manual methods. A recent survey of VRSP software packages has been published in OR/MS Today (2006).

The reduction in total distance will in itself provide environmental benefits due to the reduction in fuel consumed and the consequent pollutants. However this is generally not measured or emphasized. Palmer (2004) has studied the connection between vehicle routing and emission in the context of grocery home delivery vehicles.

There are some examples in the literature where there are some links between VRSP and the reduction of environmental pollution. These links may not be direct and such issues are discussed in the following subsections.

"Classical" vehicle routing and scheduling models aim to minimize cost (usually related to the number of vehicles and distance). This will also provide some environmental benefit compared with solutions that use unnecessary distance (because there will be some fuel saving). In their INRETS report, Pronello and André (2000) suggest that existing models to measure the pollution caused by a set of vehicle routes may be unreliable. This is because reliable pollution models require input measures which are not normally part of the output of VRSP models. For example, the time spent travelling by a vehicle when the engine is cold may have a significant effect on the pollution produced. Without these linking models it is difficult to quantify the environmental benefits of different VRSP solutions. 
Even if it is difficult to measure the precise environmental benefit, there should be some value in versions of VRSP models that consider alternative objectives to pure economic considerations. For example, the time-dependent vehicle routing models represent an approach which should indirectly produce less pollution because vehicles will tend to be directed away from congestion.

\subsection{Time-dependent vehicle routing}

The time dependent vehicle routing and scheduling problem (TDVRSP) consists in optimally routing a fleet of vehicles of fixed capacity when the traveling times between nodes depend on the time of the day that the trip on that arc was initiated. The optimization consists in finding the solution that minimizes the number of tours (the number of vehicles used) and the total traveling time. The traveling time is calculated by knowing the departing time and an accurate estimate of the average speed of the vehicle while traveling on the arc. This version of the VRSP is motivated by the fact that in many circumstances, traffic conditions cannot be ignored, because at peak times, traffic congestion on popular routes will cause delays. By minimizing the total traveling time, the solutions produced will tend to direct vehicles to roads where they can travel at a faster speed instead of being caught in congestion. It may even be that some solutions imply a greater total travel distance, but there is likely to be environmental benefit because less pollution is created when vehicles are traveling at the best speeds for the environment and for shorter times. Examples of this approach can be found in Donati et al. (2003) and Malandraki and Daskin (1992).

In fact when dealing with time constraints, like the delivery time windows for the customers, the optimal solutions known for the classic case become infeasible and the degree of infeasibility increases with the variability of traffic conditions. So an additional benefit of this approach is that it enables time window constraints to be satisfied more reliably. For the time dependent model, the travel times may also depend on other factors such as the day of the week, or the season of the year. These ideas have been treated in Haghani and Jung (2005) and Chen et al. (2006). More recently, Eglese et al. (2006) discussed the issues involved in order to construct a database of road times for a road network. More details are developed in Maden (2006).

The data requirements for the TDVRSP are significantly higher than for conventional models. Instead of simply requiring a distance between nodes on the graph representing the road network, a set of travel times are also required for every time interval defined. The shortest time path between any two nodes may be different depending on the time of travel. This is developed in Fu and Rilett (2000).

The TDVRSP approach is therefore likely to achieve environmental benefits, but in an indirect way and none of the articles referenced directly measure the environmental benefit of this approach.

\section{Conclusions}

This paper has described the field covered by Green Logistics and described some of the new problems that arise when the objectives considered are not simply eco- 
nomic, but involve wider environmental and social considerations too. There are many different types of operational research models that have key roles to play in dealing with Green Logistics issues, but in this paper we have concentrated on describing areas where combinatorial optimization is central to the design of acceptable solutions. It is expected that as environmental factors assume increasing importance, the effective use of combinatorial optimization theories and techniques will be needed to meet the challenges of new problems.

There is a research consortium in the UK working on many different aspects of Green Logistics models and more information can be found on the website www.greenlogistics.org. The Green Logistics project includes several work modules that relate to topics covered in this review such as reverse logistics and the effect of vehicle routing and scheduling policies on the Green Logistics agenda.

\section{References}

Agarwal Y, Mathur K, Salkin HM (1989) A set-partitioning-based exact algorithm for the vehicle routing problem. Networks 19:731-749

Aminu UF, Eglese RW (2006) A constraint programming aproach to the Chinese Postman problem with time windows. Comput Oper Res 33:3423-3431

Ammons JC, Realff MJ, Newton D (1999) Carpet recycling: determining the reverse production system design. J PolymPlast Technol Eng 38(3):547-567

Archetti C, Speranza MG (2004) Vehicle routing in the 1-skip collection problem. J Oper Res Soc 55(7):717727

Baldacci R, Maniezzo V (2006) Exact methods based on node-routing formulations for undirected arcrouting problems. Networks 47:52-60

Barros AI, Dekker R, Scholten V (1998) A two-level network for recycling sand: a case study. Eur J Oper Res 110(2): 199-214

Belenguera J-M, Benaventa E, Lacomme P, Prins C (2006) Lower and upper bounds for the mixed capacitated arc routing problem. Comput Oper Res 33:3363-3383

Benavent E, Campos V, Corberán A (1992) The capacitated arc routing problem: lower bounds. Networks 22:669-690

Beullens P, Muyldermans L, Cattrysse D, Van Oudheusden D (2003) A guided local search heuristic for the capacitated arc routing problem. Eur J Oper Res 147:629-643

Bodin L, Mingozzi A, Baldacci R, Ball M (2000) The rollon-rolloff vehicle routing problem. Transport Sci 34:271-288

Bramel J, Simchi-Levi D (1997) The logic of logistics: theory, algorithms, and applications for logistics management. Springer, Berlin

Brandão J, Eglese RW (2006) A deterministic tabu search algorithm for the capacitated arc routing problem. Comput Oper Res (in press) doi: 10.106/j.cor.2006.07.007

De Brito MP, Van Der Laan EA (2003) Inventory management with returns: the impact of misinformation. Erasmus research institute series, Erasmus University Rotterdam, Rotterdam, The Netherlands

Chen H-K, Hsueh C-F, Chang M-S (2006) The real-time time-dependent vehicle routing problem. Transp Res Part E: Logist Transp Rev 42(5):383-408

Chu F, Labadi N, Prins C (2005) Heuristics for the periodic capacitated arc routing problem. J Intell Manufact 16(2):243-251

Chu F, Labadi N, Prins C (2006) A scatter search for the periodic capacitated arc routing problem. Eur J Oper Res 169(2):586-605

Clarke G, Wright JW (1964) Scheduling of vehicles from a central depot to a number of delivery points. Oper Res 12(4):568-581

Cordeau J-F, Laporte G (2004) Tabu search heuristics for the vehicle routing problem. In: Rego C, Alidaee B (eds) Metaheuristic optimization via memory and evolution: tabu search and scatter search, Kluwer, Boston, pp 145-163 
Cordeau J-F, Gendreau M, Hertz A, Laporte G, Sormany J-S (2005) New heuristics for the vehicle routing problem. In: Langevin A, Riopel D (eds) Logistics systems: design and optimization. Springer, New York, pp 279-297

Dantzig GB, Ramser JM (1959) The truck dispatching problem. Manag Sci 6:81-91

Dekker R, Fleischmann M, Inderfurth K, Van Wassenhove LN (eds), (2004) Reverse logistics: quantitative models for closed-loop supply chains, Springer, Berlin

Dellaert N, Jeunet J (2000) Solving large unconstrained multilevel lot-sizing problems using a hybrid genetic algorithm. Int J Prod Res 38(5):1083-1099

Donati A, Gambardella L, Casagrande N, Rizzoli A, Montemanni R (2003) Time dependent vehicle routing problem with an ant colony system. Internal IDSIA report, IDSIA-02-03

Dowlatshahi S (2000) Developing a theory of reverse logistics. Interfaces 30(3):143-155

Dror M (ed) (2000) Arc routing: theory solutions and applications. Kluwer, Boston

Eglese RW, Li LYO (1996) A tabu search based heuristic for arc routing with a capacity constraint and time deadline. In: Osman IH, Kelly JP (eds), Metaheuristics: theory and applications. Kluwer, Boston, pp 633-650

Eglese RW, Maden W, Slater A (2006) A road timetable ${ }^{\mathrm{TM}}$ to aid vehicle routing and scheduling. Comput Oper Res 33:3508-3519

Fleischmann M (2001) Quantitative models for reverse logistics. Springer, New York

Fleischmann M, Bloemhof-Ruwaard JM, Dekker R, Van Der Laan EA, Van Nunen JAEE, Van Wassenhove LN (1997) Quantitative models for reverse logistics: a review. Eur J Oper Res 103:1-17

Fleischmann M, Krikke HR, Dekker R, Flapper SDP (2000) A characterisation of logistics networks for product recovery. OMEGA Int J Manag Sci 28(6):653-666

Fu LP, Rilett LR (2000) Estimation of time-dependent, stochastic route travel times using artificial neural networks. Transport Plan Technol 24(1):25-48

Fukasawa R, Longo H, Lysgaard J, Poggi de Aragão M, Reis M, Uchoa E, Werneck RF (2006) Robust branch-and-cut-and-price for the capacitated vehicle routing problem. Math Program Ser A B 106(3):491-511

Gendreau M, Laporte G, Potvin J-Y (2002) Metaheuristics for the capacitated VRP. In: Toth P, Vigo D (eds) The vehicle routing problem. SIAM Monographs on Discrete Mathematics and Applications, Philadelphia, pp 129-154

Giannikos I (1998) A multi-objective programming model for locating treatment sites and routing hazardous wastes. Eur J Oper Res 104:333-342

Golden BL, Assad AA (1988) Vehicle routing: methods and studies. North-Holland, Amsterdam

Golden BL, Wong RT (1981) Capacitated arc routing problems. Networks 11:305-315

Golden BL, de Armon JS, Baker EK (1983) Computational experiments with algorithms for a class of routing problems. Comput Oper Res 10(1):47-59

Greistorfer P (2003) A tabu scatter search metaheuristic for the arc routing problem. Comput Ind Eng 44(2):249-266

Haghani A, Jung S (2005) A dynamic vehicle routing problem with time-dependent travel times. Comput Oper Res 32(11):2959-2986

Hertz A, Laporte G, Mittaz M (2000) A tabu search heuristic for the capacitated arc routing problem. Oper Res 48(1):129-135

Hertz A, Laporte G, Mittaz M (2001) A variable neighborhood descent algorithm for the undirected capacitated arc routing problem. Transport Sci 35:425-434

Hu T-L, Sheu J-B, Huang K-H (2002) A reverse logistics cost minimization model for the treatment of hazardous wastes. Transport Res Part E Logist Transport Rev 38:457-473

Jayaraman V, Guide VDR Jr, Srivastava R (1999) A closed-loop logistics model for remanufacturing. J Oper Res Soc 50(5):497-508

Johnson LA, Montgomery DC (1974) Operations research in production planning, scheduling, and inventory control. Wiley, New York

Krikke HR (1998) Recovery strategies and reverse logistic network design. Thesis, University of Twente, Enschede, The Netherlands

Krikke HR, Van Harten A, Schuur PC (1999) Business case Océ: reverse logistic network re-design for copiers. OR Spektrum 21(3):381-409

Krikke HR, Bloemhof-Ruwaard J, Van Wassenhove L (2001) Design of closed loop supply chains: a production and return network for refrigerators. Erim report series research in management, Ers-2001-45-Lis 
Kroon L, Vrijens G (1995) Returnable containers: an example of reverse logistics. Int J Phys Distrib Logist Manag 25(2):56-68

Lacomme P, Prins C, Sevaux M (2003) Multiobjective capacitated arc routing problem. In: Fonseca C, Fleming PJ, Zitzler E, Thiele T (eds) Proceedings evolutionary multi-criterion optimization: second international conference, EMO 2003, Faro, Portugal, 8-11 April 2003, LNCS 2632, pp 550-564, Springer, Berlin

Lacomme P, Prins C, Ramdane-Cherif W (2004) Competitive memetic algorithms for arc routing problems. Ann Oper Res 131(1-4):159-185

Lacomme P, Prins C, Ramdane-Cherif W (2005) Evolutionary algorithms for periodic arc routing problems, Eur J Oper Res 165(2):535-553

Laporte G, Nobert Y (1987) Exact algorithms for the vehicle routing problem. Ann Discrete Math 31:147184

Laporte G, Semet F (2002) Classical heuristics for the capacitated VRP. In: Toth P, Vigo D (eds) The vehicle routing problem. SIAM Monographs on Discrete Mathematics and Applications, Philadelphia, pp 109-128

Longo H, Poggi de Aragão M, Uchoa E (2006) Solving capacitated arc routing problems using a transformation to the CVRP. Comput Oper Res 33:1823-1837

Lysgaard J, Letchford AN, Eglese RW (2004) A new branch-and-cut algorithm for the capacitated vehicle routing problem. Math Program 100:423-445

Maden W (2006) Models and heuristics algorithms for complex routing and scheduling problems. Ph.D. dissertation, Department of Management Science, Lancaster University Management School, UK

Malandraki C, Daskin MS (1992) Time dependent vehicle routing problems: formulations, properties and heuristic algorithms. Transport Sci 26(3):185-200

Mansini R, Speranza MG (1998) A linear programming model for the separate refuse collection service. Comput Oper Res 25(7/8):659-673

Marìn A, Pelegrìn B (1998) The return plant location problem: modelling and resolution. Eur J Oper Res 104(2):375-392

De Meulemeester L, Laporte G, Louveaux FV, Semet F (1997) Optimal sequencing of skip collections and deliveries. J Oper Res Soc 48:57-64

Mondschein SV, Schilkrut A (1997) Optimal investment policies for pollution control in the copper industry. Interfaces 27(6):69-87

Moscato P (1999) Memetic algorithms: a short introduction. In: Corne D, Dorigo M, Glover F (eds) New ideas in optimization. McGraw-Hill, New York, pp 219-234

Mourão MC, Almeida T (2000) Lower-bounding and heuristic methods for a refuse collection vehicle routing problem. Eur J Oper Res 121:420-434

Nema AK, Gupta SK (1999) Multiobjective risk analysis and optimization of regional hazardous waste management system. Practice Period Hazard Toxic Radioactive Waste Manag 7:69-77

Nema AK, Gupta SK (2003) Optimization of regional hazardous waste management systems: an improved formulation. Waste Manag 19:441-451

OR/MS Today (2006) Vehicle routing software survey. http://www.lionhrtpub.com/orms/surveys/ Vehicle_Routing/vrss.html

Palmer A (2004) The environmental implications of grocery home delivery. Centre for Logistics and Supply Chain Management, Cranfield University, ELA doctorate workshop

Pearn WL, Assad A, Golden BL (1987) Transforming arc routing into node routing problems. Comput Oper Res 14:285-288

Peirce JJ, Davidson GM (1982) Linear programming in hazardous waste management. J Environ Eng 108(EE5):1014-1026

Pronello C, André M (2000) Pollutant emissions estimation in road transport models. INRETS-LTE report, vol 2007

Rogers DS, Tibben-Lembke RS (1999) Going backwards: reverse logistics trends and practices. Reverse Logistics Executive Council (RLEC), Pittsburgh

Sahoo S, Kim S, Kim B, Kraas B, Popov A (2005) Routing optimization for waste management. Interfaces 35(1):24-36

Sarkis J (2001) Greener manufacturing and operations from design to delivery and back. Greenleaf Publishing, Sheffield

Shih LH, Lin YT (2003) Multicriteria optimization for infectious medical waste collection system planning. Pract Period Hazard Toxic Radioactive Waste Manag 7:78-85 
Silver EA, Meal HC (1973) A heuristic for selecting lot size requirements for the case of a deterministic time-varying demand rate and discrete opportunities for replenishment. Prod Invent Manag 14:64-74

Silver EA, Pyke DF, Peterson R (1996) Inventory management and production planning and scheduling, 3rd edn (1998). Wiley, New York

Spengler T, Piichert H, Penkuhn T, Rentz O (1997) Environmental integrated production and recycling management. Eur J Oper Res 97(2):308-326

Teixeira J, Antunes AP, de Sousa JP (2004) Recyclable waste collection planning: a case study. Eur J Oper Res 158:543-554

Teunter RH, Bayindir ZP, Van Den Heuvel W (2006) Dynamic lot sizing with product returns and remanufacturing. Int J Prod Res 44(20):4377-4400

Toth P, Vigo D (eds) (2001) The vehicle routing problem. SIAM Monographs on Discrete Mathematics and Applications, Philadelphia

Ulusoy G (1985) The fleet size and mix problem for capacitated arc routing. Eur J Oper Res 22:329-337

Van Den Heuvel W (2004) On the complexity of the economic lot-sizing problem with remanufacturing options. Econometric institute report. Technical report EI 2004-46, Econometric Institute, Erasmus University Rotterdam, The Netherlands

Wagner HM, Whitin TM (1958) A dynamic version of the economic lot size model. Manag Sci 5:86-96

White CD, Masnet E, Meisner Rosen C, Beckman SL (2003) Product recovery with some byte: an overview of management challenges and environmental consequences in reverse manufacturing for the computer industry. J Cleaner Prod 11:445-458 